\title{
Retraction Note to: Convergence of Weighted Sums for Arrays of Negatively Dependent Random Variables and Its Applications
}

\author{
Jong-Il Baek • Sung-Tae Park
}

Published online: 18 May 2013

(C) Springer Science+Business Media New York 2013

\section{Retraction Note to: J Theor Probab (2010) 23: 362-377 DOI 10.1007/s10959-008-0198-y}

The Editor-in-Chief of Journal of Theoretical Probability has found that a duplicate of "Convergence of Weighted Sums for Arrays of Negatively Dependent Random Variables and Its Applications" by Jong-Il Baek and Sung-Tae Park, Journal of Theoretical Probability, Volume 23, Issue 2, pages 362-377, was submitted simultaneously on May 31, 2008 to both this journal and Journal of Statistical Planning and Inference and was published, with the explicit consent of the authors, in Journal of Statistical Planning and Inference many months after it was published in this journal. One of the conditions of submission of a paper for publication is that authors declare explicitly that the paper is not under consideration for publication elsewhere. This article thus represents a severe abuse of the scientific publishing system.

For this reason, the Editor-in-Chief of Journal of Theoretical Probability, in agreement with the publisher, hereby retracts this article.

The online version of the original article can be found under doi:10.1007/s10959-008-0198-y.

J.-I. Baek $(\varangle)$

Division of Mathematics \& Informational Statistics, and Institute of Basic Natural Science, Wonkwang University, IkSan 570-749, South Korea

e-mail: jibaek@wonkwang.ac.kr

S.-T. Park

Division of Business, and Business and Economic Research Institute, Wonkwang University, IkSan 570-749, South Korea

e-mail: pst@wonkwang.ac.kr 
As a sanction, Journal of Theoretical Probability will not allow the authors of the article to participate in the journal in any way until January 1, 2018.

James Allen Fill Editor-in-Chief 